\title{
Trajectories of childhood body mass index are associated with adolescent sagittal standing posture
}

Type of manuscript: Original Article

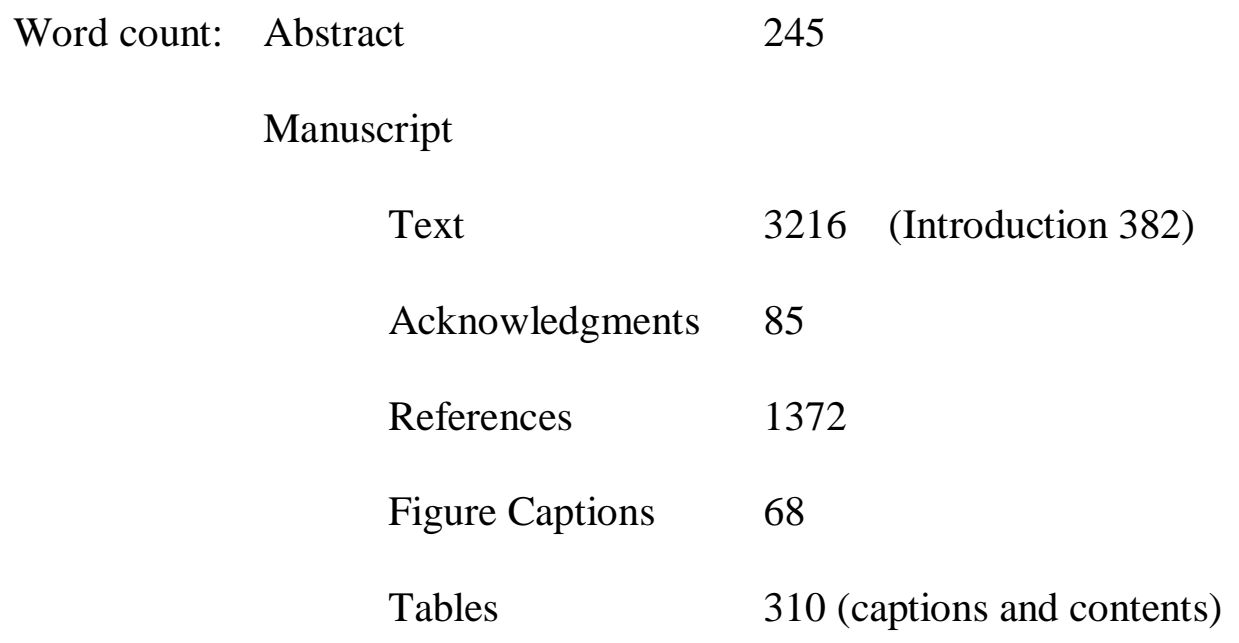

Number of References $\quad 56$

Number of Tables $\quad 2$

Number of Figures $\quad 4$

\section{Authors}

Dr Anne J Smith, $\mathrm{PhD}^{1,2}$

Professor Peter Bruce O’Sullivan, $\mathrm{PhD}^{1,2}$

Dr Darren John Beales, $\mathrm{PhD}^{1}$

Professor Nick de Klerk, $\mathrm{PhD}^{2}$

Professor Leon M Straker, $\mathrm{PhD}^{1,2}$ 


\section{Author Affiliations}

${ }^{1}$ School of Physiotherapy and Curtin Health Innovation Research Institute, Curtin University of Technology, GPO Box U1987, Perth, Western Australia, 6845

${ }^{2}$ Telethon Institute for Child Health Research and Centre for Child Health Research,100

Roberts Road, Subiaco, Western Australia, 6008

\section{Corresponding Author}

Dr Anne Smith

School of Physiotherapy

Curtin University of Technology

GPO Box U1987

Perth, Western Australia, 6845

(w) 61892663629

(f) 61892663699

Anne.Smith@exchange.curtin.edu.au 


\begin{abstract}
Objectives

To identify distinct age-related trajectory classes of body mass index (BMI) z-scores from childhood to adolescence, and to examine the association of these trajectories with measures of standing sagittal spinal alignment at 14 years of age.

\section{Methods}

Adolescents participating in the Western Australian Pregnancy Cohort (Raine) Study contributed data to the study $(n=1373)$. Age and gender specific $\mathrm{z}$-scores for BMI were obtained from height and weight at age 3, 5, 10 and 14 years. Latent class group analysis was used to identify six distinct trajectory classes of BMI z-score. At age 14 years, adolescents were categorised into one of four subgroups of sagittal spinal posture using k-means cluster analysis of photographic measures of lumbar lordosis, thoracic kyphosis and trunk sway. Regression modeling was used to assess the relationship between postural angles and subgroups and different BMI trajectory classes, adjusting for gender. Results

Six trajectory classes of BMI z-score were estimated; Very Low (4\%), Low (24\%), Average (34\%), Ascending (6\%), Moderate High (26\%) and Very High (6\%). The proportions of postural subgroups at age 14 were; Neutral (29\%), Flat (22\%), Sway (27\%) and Hyperlordotic (22\%). BMI trajectory class was strongly associated with postural subgroup, with significantly higher proportions of adolescents in the Very High, High and Ascending BMI trajectory classes displaying a Hyperlordotic or Sway posture than a Neutral posture at age 14 .

Conclusions 
This prospective study provides evidence that childhood obesity, and how it develops, is associated with standing sagittal postural alignment in adolescence.

\section{Key Words}

body mass index, standing posture, obesity, adolescence 


\section{Introduction}

Obesity has increased in adults and children (1-3). This is concerning, as obesity is a risk factor for many health disorders. The development of obesity has been investigated utilising latent class analysis to identify different growth trajectories of body mass index (BMI) during childhood and adolescence, followed by assessment of relationships between trajectories and multiple factors (4-7). Using this approach chronic childhood obesity has been linked with increased risk of depression in males and oppositional defiant disorder in both sexes (5). This method has merit for investigating the impact of obesity on musculoskeletal development, an area in need of more research (8). One aspect of this is the relationship between obesity and posture.

In adults there appears to be a relationship between sagittal spinal alignment and load secondary to body weight. Obese subjects have increased thoracic kyphosis and hyperlordosis in the lumbar spine during usual standing (9). Pregnancy may also result in increased lumbar lordosis in usual standing $(10,11)$, though not always (12).

In children and adolescents there also appears to be a relationship between standing posture and weight. Greater weight at 14 is associated with hyperlordotic and sway standing postures (13). Furthermore, findings from cross-sectional studies with multiple age groups show weight during growth to be a factor in sagittal standing posture development $(14,15)$. In contrast, a longitudinal study of 11 to 22 year olds found no relationship between BMI and the development of thoracic kyphosis (16). Sagittal spinal 
posture development may be influenced by genetics (17), gender (16, 18-22), exercise levels (23), height (14), school furniture (24) and generation (25).

Significant individual variation in sagittal standing posture development through childhood and adolescence has been reported (16, 20, 22, 26, 27). This may represent deviations from one 'ideal’ posture. However, four distinct subgroups of standing postures have been identified in adults (28) and adolescents (13); (i) Neutral, (ii) Sway, (iii) Flat Back, and (iv) Hyperlordotic. Consideration of standing posture subgroups may clarify some of the inconsistency in the literature regarding factors influential in posture development.

The aims of the present study were; (i) identify distinct classes of BMI trajectories from childhood to early adolescence, and (ii) evaluate the association between BMI trajectories with subgroups of standing sagittal spinal alignment at 14 . Adolescence is an important time in the development of back pain $(29,30)$. Improved understanding of the role of obesity/BMI in posture development is needed for improved prevention and management strategies for posture related back pain. 


\section{Methods}

Data was obtained from the Western Australian Pregnancy Cohort (Raine) Study (www.rainestudy.org.au). This long-term project began was formed as a pregnancy cohort in which 2,900 women attending antenatal clinics at a tertiary level obstetric hospital in Perth, Western Australia were enrolled in a controlled trial between 1989 and 1991. 2,868 children born to 2,804 mothers remained with the study to form the Western Australian Pregnancy Cohort (Raine) Study, and these children have been followed at birth,1, 2, 3, 5, 8, 10, and 14 years of age. This cohort has a higher proportion of highrisk births compared with the general Western Australia population (31), consistent with the initial subject recruitment occurring at a specialist maternity hospital. The sociodemographic characteristics of the cohort mirrors those of the general Western Australian population, except that it has a lower proportion of fathers employed in managerial positions with a concurrent higher proportion in professional positions. The ethnicity of the cohort is largely Caucasian (93\%). Children with congenital abnormalities were excluded. Premature (< 37 weeks gestation) and multiple births (50 sets of twins, 2 sets of triplets) were included as adjustment for these factors in subsequent analyses had negligible effects on the parameters of interest in this study.

\section{Standing posture assessment}

Standing sagittal thoracolumbar posture was assessed in 1373 adolescents of mean age $14.1 \pm 0.2$ years. Retro-reflective markers were placed on the C7 and T12 
spinous processes and right anterior superior iliac spine (ASIS), greater trochanter and lateral malleolus. Lateral photographs were taken in usual standing looking straight ahead. Marker points were digitised by a single research assistant using the Peak Motus motion analysis system (Peak Performance Technologies Inc.; CO, USA) and three angular measures describing thoraco-lumbo-pelvic alignment were calculated; sway angle, trunk angle and lumbar angle (see Fig. 1). This procedure is described in detail elsewhere (32). Non-hierarchical (K-means) cluster analysis of the standardised scores for the three postural measures was performed to group sagittal standing posture into 4 groups: Neutral, Sway, Flat, or Hyperlordotic, as previously described (13).

BMI

BMI was calculated at mean age (standard deviation) of 3.1(0.1), 5.9(0.2), 8.1(0.4), 10.6(0.2) and 14.1(0.2) years. BMI analysis is complicated as the relationship between body mass and height changes over childhood, with different values of BMI representing different cut-offs for definitions of overweight and obesity at different ages (33). Therefore the United States of America Centres for Disease Control and Prevention BoxCox transformation (34) was used to obtain age and gender specific z-scores for BMI, as recommended (35), using a freely available SAS program (36).

Trajectory analysis of BMI z-sores

There were 2,397 subjects with BMI data from at least one timepoint, with $80 \%$ having data for three or more. Multilevel mixed-effects linear regression is a latent growth curve 
model assuming a continuous, multivariate normal distribution of intercept and slope parameters within the population. In contrast, Latent Class Group Analysis (LCGA) uses finite mixture models to estimate discrete groupings of trajectory parameters estimated using maximum likelihood. As the hypothesis that children may have different pathways to being overweight has some recent support using $\operatorname{LCGA}(4,5,7)$, this technique was used to form a categorical variable describing the trajectories of BMI z-score. LCGA was performed within SAS using the macro PROC TRAJ (37). A series of models using all available data estimating two to eight latent trajectory classes with linear and quadratic terms for each group was systematically fitted and compared using the Bayesian Information Criterion (BIC) statistic. The choice of the number of groups was therefore guided by the goal of analysis and confirmation of model adequacy based on posterior probability diagnostics (38). Model validity was confirmed by replicating the latent class solution by random split-half sampling. Subjects were assigned to the trajectory group for which they had the highest posterior probability of membership.

\section{BMI trajectories and standing posture subgroup}

Multinomial logistic regression modeling was used to assess the relationship between posture subgroups ( $\mathrm{n}=1373$ ) and different BMI trajectories, adjusting for gender. The possibility of uncertainty in trajectory allocation influencing analysis results was checked using a model which jointly estimates the parameters defining the trajectories themselves and the association of posture/gender covariates with the probabilities of trajectory group membership (38). 
Statistical analysis was performed using SAS 9.1 (SAS Institute, Cary NC) and

Stata/IC 10.1 (Statacorp LP, College Station TX) and SPSS 13.0 (SPSS Inc.,

Chicago, USA). A p value less than 0.05 was adopted for significance testing. 


\section{Results}

\section{Standing posture subgroups}

Characteristics of the four posture subgroups are displayed in Figure 3, with specific angular values in Table 1. The proportions in each subgroup (Figure 3, Table 1) were similar to those previously reported in a smaller subgroup of these subjects (13). There was a significant difference in the gender proportions within posture clusters, with a higher than expected proportion of males in the Flat subgroup $\left(\chi^{2}=27.8, p<0.001\right)$, as previously reported (13).

\section{Latent trajectories of BMI z-sores}

A six class model was selected as best describing the trajectories of BMI z-scores. Although the BIC statistic indicated a progressively better fit with the addition of each class, improvement in fit displayed a relative plateau at the six class solution. The six class model revealed an 'ascending' trajectory which was not identified in a five class model, and addition of further classes did not reveal further ascending or descending classes but rather split existing classes into finer gradations of the relatively stable trajectories. Split half random sampling of the six class model identified similar proportions of the trajectories identified initially. The six class solution demonstrated good model fit based upon posterior probability diagnostics; average posterior probabilities of membership for each class were all above 0.75 , odds of correct classification ranged from 8 to 250 for the six classes, and there was close correspondence between estimated population proportions and sample class proportions. 
The six class model (Figure 2), consisted of: (i). a 'Very Low' class displaying a slight linear increase in very low scores (4.2\% of the sample), (ii) a 'Low' class displaying below average scores (23.6\%), (iii) an ‘Average’ class displaying average scores following a slight initial decrease (33.6\%), (iv) an 'Ascending' class with below average scores at year 3 which increased to above average scores during childhood with some leveling off into adolescence (6.5\%), (v) a ‘Moderate High’ class displaying slightly increasing, above average scores over childhood leveling to scores in the overweight range (i.e. above $85^{\text {th }}$ percentile) of just above $\mathrm{z}=1$ in late childhood (26.1\%) and (vi) a 'High' class displaying consistently high scores in the overweight range (i.e. above $95^{\text {th }}$ percentile) of approximately $z=2$ (6.0\%). There were approximately equal numbers of males and females in each class, except the 'high' class of which 87 of 144 (60.4\%) members were male, but this was not a statistically significant difference $\left(\chi^{2}{ }_{5}=8.22\right.$, $\mathrm{p}=0.145)$.

\section{Association between trajectories of BMI z-scores and posture subgroups}

There were significant associations between posture subgroups and the latent classes of BMI z-scores trajectories (Table 2, Figure 4). Figure 4 displays higher proportions of the Very High, High and Ascending classes and lower proportions of the two lower classes in the Hyperlordotic subgroup compared to the Neutral subgroup. A similar though less extreme pattern of contrast was observed in the Sway compared with Neutral subgroup. The Flat and Neutral subgroups had similar proportions of each trajectory class. 
The statistical significance of these patterns was confirmed by multinomial logistic regression analysis adjusted for gender (Table 2). The three above-average trajectories, particularly Very High, displayed significantly higher risk than the Average trajectory for membership of the Hyperlordotic subgroup versus the Neutral subgroup, while the Low trajectory displayed a significantly lower risk (Table 2). Likewise, the three aboveaverage trajectories had significantly higher risk than the Average trajectory for membership of the Sway subgroup versus the Neutral subgroup, although the risk ratios for this group were lower than those of the Hyperlordotic subgroup (see Table 2). The High trajectory did not display a significantly greater risk than the Ascending trajectory for membership of the Hyperlordotic subgroup versus the Neutral subgroup $(p=0.20)$ or for membership risk of the Sway subgroup $(\mathrm{p}=0.57)$. There was no significant difference in risk for membership of the Flat subgroup versus the Neutral subgroup for any trajectory class.

The three angular posture measures that were used to estimate the posture subgroups were significantly associated with BMI z-score trajectory class membership (Table 2). The Very High trajectory had a mean Lumbar angle $3.2^{0}$ less than the Average trajectory (95\% CI: $0.7^{0}$ to $5.7^{0}, \mathrm{p}=0.013$ ), and the High trajectory had a mean Lumbar angle $2.8^{0}$ less (95\% CI: $1.4^{0}$ to $\left.4.3^{0}, \mathrm{p}<0.001\right)$. The Very High trajectory had a mean Trunk angle $10.5^{0}$ more than the Average trajectory (95\% CI: $8.6^{0}$ to $12.5^{0}, \mathrm{p}<0.001$ ), the High trajectory $3.4^{0}$ more (95\% CI: $2.3^{0}$ to $\left.4.6^{0}, \mathrm{p}<0.001\right)$, the Ascending trajectory $3.4^{0}$ more (95\% CI: $1.7^{0}$ to $5.0^{0}, \mathrm{p}<0.001$ ), and the Low trajectory $1.7^{0}$ less (95\% CI: $0.6^{0}$ to $2.8^{0}$, $\mathrm{p}=0.003$ ). The High trajectory had a mean Sway angle $1.1^{0}$ less than the Average 
trajectory (95\% CI: $0.4^{0}$ to $\left.1.8^{0}, \mathrm{p}=0.004\right)$, while the Very Low trajectory had $2.3^{0}$ more (95\% CI: $0.9^{0}$ to $3.8^{0}, \mathrm{p}=0.002$ ). The High trajectory did not display significantly different posture angles to the Ascending trajectory $(\mathrm{p}=0.32,0.92$ and 0.13 for Lumbar, Trunk and Sway angle respectively). 


\section{Discussion}

BMI z-score trajectories

This study identified six trajectory classes of BMI z-scores over childhood and early adolescence. Five of these were relatively stable with only one exhibiting an ascending pattern. The two trajectories with the highest z-scores showed tracking of overweight and obesity from childhood into adolescence. The two lowest trajectories did not appear to differ substantially in outcomes assessed in this study and could be combined in future studies. A number of recent studies have used within-person latent growth mixture modeling to investigate the presence of distinct patterns of weight status over childhood and adolescence. Li et al (4) estimated three latent trajectories in children aged 2-12 years based on binary categories of above and below the $95^{\text {th }}$ percentile for age and gender as defined by the CDC growth charts; never overweight (84\%), early onset overweight (11\%) and late onset overweight (5\%). Mustillo et al (5) estimated four trajectories in adolescents aged 9-16 years, based on the same binary categories; no obesity (73\%), chronic obesity (15\%), childhood obesity (5\%) and adolescent obesity (7\%). Ventura et al (7) estimated four latent trajectories in girls aged 5 to 15 years based on raw BMI scores, which were named based on how they related to CDC growth chart percentile curves; upward percentile crossing (14\%), delayed downward percentile crossing (20\%), $60^{\text {th }}$ percentile tracking (29\%) and $50^{\text {th }}$ percentile tracking (37\%). Nonnemaker et al (6) also used raw BMI scores to estimate four latent trajectories in an accelerated longitudinal study of adolescents and young adults aged from 12 -23; high 
risk for obesity (4\%), moderate-to-high risk (16\%), low-to-moderate risk (36\%) and low risk (44\%).

Use of different indicators of weight status makes comparisons across different models difficult. Categorical approaches define trajectories only in terms of the presence or absence of overweight, so trajectories become ones of 'likelihood of being classified as overweight'. Use of raw BMI scores allows further characterization of trajectories in subjects whose scores over the time period do not approach overweight status. However, the use of raw BMI scores do not allow any tracking of a subjects' rank order within BMI distributions. Changes in means and shapes of BMI distributions over gender and ages complicates interpretation of trajectories based upon raw BMI scores. Comparisons between the trajectory classes estimated in this study and previous studies are further complicated by differences in span of time measured $(5,6)$ measured versus self-report BMI (6), both versus single gender (7), traditional versus accelerated longitudinal design (6) and population differences in race/ethnicity $(4,6)$.

Using age and gender specific z-scores for BMI enabled estimation of trajectories at less than very high BMI levels, estimation of how individuals tracked according to their rank order of BMI in the population, eliminated the need for age and gender adjustment within the trajectory estimation procedure, and provided the most meaningful measure to examine the relationship between the change in the load of body weight on the posture of the developing spine. 
It should be emphasized that changes in BMI over childhood and adolescence is not equivalent to measuring changes in body composition. While lean body mass appears to consistently increase with increasing BMI percentile, body fat has more complex relationships dependent upon gender, age and level of BMI percentile (39). Thus increased load on the musculoskeletal system inherent to the higher level trajectories described in the present study can be comprised of various proportions of lean body tissue and fat. How this factor, plus differences in fat distribution in the body and differences in muscle bulk, effect the development of posture are important issues for further consideration.

\section{BMI trajectories and posture}

This study identified significant prospective associations between childhood BMI z-score trajectory classes and adolescent posture subgroups as well as single measures of sagittal posture. This suggests a role for body load in the development of sagittal spinal curvature across the lumbar and thoracic spine, consistent with other studies demonstrating a cross-sectional relationship between body weight and sagittal spinal posture $(14,15)$. The findings of relationships between BMI trajectories and posture subgroups are timely in light of a recent call for increased understanding of the effect of obesity on the development of the musculoskeletal system (8).

Despite similar endpoints, High and Ascending trajectories had different patterns of change in BMI z-score over childhood, with the Ascending trajectory beginning at less than average scores and gradually rising to above average scores, while the High 
trajectory displayed above average values throughout childhood. However, these two trajectory classes were at a similar increased risk for Sway or Hyperlordotic posture. This suggests that load increases in later childhood/early adolescence may be as important as increased load in early childhood in the development of hyperlordotic and sway postures.

The relationship between the higher level trajectories and non-neutral postures may not be a simple effect of load. It is known that mental state can influence posture $(40,41)$ and likewise obesity may negatively influence psychological status (5, 42-44). Thus, higher BMI could potentially negatively affect mental wellbeing that then has a secondary effect on posture. Lifestyle factors, such as exercise levels have also been reported to influence the development of posture (23). Decreased physical activity could lead to obesity and muscle deconditioning, with deconditioning then influencing posture.

Consideration of patterns of deviation of the entire thoracolumbar spine from neutral, by clinically well-recognized posture subgroups identified from the combination of measures, gave a clearer picture of the association between non-neutral postures and BMI trajectory groups than analysis by single angles, although significant differences were also observed in these measures. Not considering subgroups of spinal posture may in part account for past failure to find a relationship between BMI and standing posture (16). 


\section{Clinical implications}

The results suggest postural adaptations to body weight are occurring in the developing spine. This is cause for concern as positional change may influence the morphology of bone, disc and other spinal structures. This could provide a direct physical link to the experience of back pain.

Both single measures and subgroups of sagittal spinal posture have been associated with back pain in adolescence and adulthood $(13,45-53)$. Significantly, non-neutral standing posture subgroups at 14 are associated with increased experience of back pain (13). Adolescents in the Very High, High and Ascending BMI trajectories are at increased risk of having sagital standing postures associated with back pain. Membership of these BMI trajectories could potentially result in permanent alterations in spinal posture secondary to body load in childhood, and adolescents may carry an increased risk for poor spinal health throughout life. Obese $\left(>95^{\text {th }}\right.$ percentile BMI) and overweight $\left(>85^{\text {th }}\right.$ percentile BMI) children are at greater risk of hyperlordotic or sway postures in adolescence. The mechanism for the increased risk of LBP in these postural subgroups has been proposed to be related to increased extension loading of the spine stabilising structures (52). These postural subgroups have also been reported to be associated with specific spinal pathologies in adulthood (28) suggesting these body postures may have a detrimental effect on spinal structures across the lifespan. These findings support early targeted interventions to prevent obesity in order to reduce the burden of LBP and other related co-morbidities. 
Additionally, emerging literature suggests reciprocal associations between posture and emotion $(41,54,55)$, raising the possibility that spinal posture may have an influence upon mental health. However, the evidence for an association between sagittal spinal posture and various health conditions is currently weak due to a lack of high quality and prospective studies (56). This study highlights obesity as a potentially important confounder of the relationship between posture and health.

\section{Conclusion}

This study provides a detailed description of developmental BMI z-score trajectories, with five of six trajectory classes in the model demonstrating tracking of z-scores between the ages of 3 and 14, with the sixth displaying increasing z-scores from ages 3 to 10. Hyperlordotic and Sway standing postures were more commonly associated with Very High, High and Ascending BMI trajectories suggesting obese and overweight children are more at risk of low back pain associated with increased lumbar lordosis. 


\section{Acknowledgements}

-Funding has been received from the Australian National Health and Medical Research Council (project 323200, program 003209, fellowships 373638 and 373638), the

Telethon Institute for Child Health Research, the Raine Medical Research Foundation at the University of Western Australia, Healthway, the Arthritis Foundation of Western Australia and the Arthritis Foundation of Australia

-Data collection by Rosemary Austin, Lee Clohessy, Alex D'Vauz, Monique Robinson, Nick Sloan and Diane Wood

-Data processing by Jemma Coleman and Clare Haselgrove

-Study participants and their families 


\section{References}

1. Matthiessen J, Velsing Groth M, Fagt S, et al. Prevalence and trends in overweight and obesity among children and adolescents in Denmark. Scand J Public Health. 2008; 36(2):153-60.

2. Vuorela N, Saha MT, Salo M. Prevalence of overweight and obesity in 5- and 12year-old Finnish children in 1986 and 2006. Acta Paediatr. 2009; 98(3):507-12.

3. Zaninotto P, Head J, Stamatakis E, Wardle H, Mindell J. Trends in obesity among adults in England from 1993 to 2004 by age and social class and projections of prevalence to 2012. J Epidemiol Community Health. 2009; 63(2):140-6.

4. Li C, Goran MI, Kaur H, Nollen N, Ahluwalia JS. Developmental trajectories of overweight during childhood: role of early life factors. Obesity. 2007; 15(3):760-71.

5. Mustillo S, Worthman C, Erkanli A, Keeler G, Angold A, Costello EJ. Obesity and psychiatric disorder: developmental trajectories. Pediatrics. 2003; 111(4 Pt 1):851-9.

6. Nonnemaker JM, Morgan-Lopez AA, Pais JM, Finkelstein EA. Youth BMI trajectories: evidence from the NLSY97. Obesity. 2009; 17(6):1274-80.

7. Ventura AK, Loken E, Birch LL. Developmental trajectories of girls' BMI across childhood and adolescence. Obesity. 2009; 17(11):2067-74. 
8. Chan G, Chen CT. Musculoskeletal effects of obesity. Curr Opin Pediatr. 2009; 21(1):65-70.

9. Fabris de Souza SA, Faintuch J, Valezi AC, et al. Postural changes in morbidly obese patients. Obes Surg. 2005; 15(7):1013-6.

10. Dumas GA, Reid JG, Wolfe LA, Griffin MP, McGrath MJ. Exercise, posture, and back pain during pregnancy. Clin Biomech. 1995; 10(2):98-103.

11. Franklin ME, Conner-Kerr T. An analysis of posture and back pain in the first and third trimesters of pregnancy. J Orthop Sports Phys Ther. 1998; 28(3):133-8.

12. Gilleard WL, Crosbie J, Smith R. Static trunk posture in sitting and standing during pregnancy and early postpartum. Arch Phys Med Rehabil. 2002; 83(12):1739-44.

13. Smith A, O'Sullivan P, Straker L. Classification of sagittal thoraco-lumbo-pelvic alignment of the adolescent spine in standing and its relationship to low back pain. Spine. 2008; 33(19):2101-7.

14. McEvoy MP, Grimmer K. Reliability of upright posture measurements in primary school children. BMC Musculoskelet Disord. 2005; 6:35.

15. Propst-Proctor SL, Bleck EE. Radiographic determination of lordosis and kyphosis in normal and scoliotic children. J Pediatr Orthop. 1983; 3(3):344-6. 
16. Poussa MS, Heliovaara MM, Seitsamo JT, Kononen MH, Hurmerinta KA, Nissinen MJ. Development of spinal posture in a cohort of children from the age of 11 to 22 years. Eur Spine J. 2005; 14(8):738-42.

17. Choufani E, Jouve JL, Pomero V, Adalian P, Chaumoitre K, Panuel M. Lumbosacral lordosis in fetal spine: genetic or mechanic parameter. Eur Spine J. 2009.

18. Fon GT, Pitt MJ, Thies AC, Jr. Thoracic kyphosis: range in normal subjects. AJR Am J Roentgenol. 1980; 134(5):979-83.

19. Mellin G, Poussa M. Spinal mobility and posture in 8- to 16-year-old children. J Orthop Res. 1992; 10(2):211-6.

20. Voutsinas SA, MacEwen GD. Sagittal profiles of the spine. Clin Orthop Relat Res. 1986; (210):235-42.

21. Widhe T. Spine: posture, mobility and pain. A longitudinal study from childhood to adolescence. Eur Spine J. 2001; 10(2):118-23.

22. Willner S, Johnson B. Thoracic kyphosis and lumbar lordosis during the growth period in children. Acta Paediatr Scand. 1983; 72(6):873-8. 
23. Wojtys EM, Ashton-Miller JA, Huston LJ, Moga PJ. The association between athletic training time and the sagittal curvature of the immature spine. Am J Sports Med. 2000; 28(4):490-8.

24. Koskelo R, Vuorikari K, Hanninen O. Sitting and standing postures are corrected by adjustable furniture with lowered muscle tension in high-school students. Ergonomics. 2007; 50(10):1643-56.

25. Murata Y, Utsumi T, Hanaoka E, Takahashi K, Yamagata M, Moriya H. Changes in lumbar lordosis in young patients with low back pain during a 10-year period. J Orthop Sci. 2002; 7(6):618-22.

26. Boseker EH, Moe JH, Winter RB, Koop SE. Determination of "normal" thoracic kyphosis: a roentgenographic study of 121 "normal" children. J Pediatr Orthop. 2000; 20(6):796-8.

27. Cil A, Yazici M, Uzumcugil A, et al. The evolution of sagittal segmental alignment of the spine during childhood. Spine. 2004; 30(1):93-100.

28. Roussouly P, Gollogly S, Berthonnaud E, Dimnet J. Classification of the normal variation in the sagittal alignment of the human lumbar spine and pelvis in the standing position. Spine. 2005; 30(3):346-53. 
29. Leboeuf-Yde C, Kyvik KO. At what age does low back pain become a common problem? A study of 29,424 individuals aged 12-41 years. Spine. 1998; 23(2):228-34.

30. Sato T, Ito T, Hirano T, et al. Low back pain in childhood and adolescence: a cross-sectional study in Niigata City. Eur Spine J. 2008; 17(11):1441-7.

31. Kendall GE. Children in families in communities: a modified conceptual framework and an analytical strategy for identifying patterns of factors associated with developmental health problems in childhood. Perth: University of Western Australia; 2003.

32. Perry M, Smith AJ, Straker LM, Coleman JL, O’Sullivan PB. Reliability of sagittal photographic spinal posture assessment in adolescents. Advances in Physiotherapy. 2008; 10(1):66-75.

33. Cole TJ, Bellizzi MC, Flegal KM, Dietz WH. Establishing a standard definition for child overweight and obesity worldwide: international survey. BMJ. 2000; 320(7244):1240-3.

34. Kuczmarski RJ, Ogden CL, Grummer-Strawn LM, et al. CDC growth charts: United States. Adv Data. 2000; (314):1-27. 
35. Australian Government Department of Health and Aging. Clinical Practice Guidelines for the Management of Overweight and Obesity in Children and Adolescents Part 2: Definition and Measurement of Overweight and Obesity in Children and Adolescents. 2003;

http://www.health.gov.au/internet/main/publishing.nsf/Content/obesityguidelinesguidelines-children.htm:Accessed 5 Aug 2008.

36. Centers for Disease Control and Prevention. A SAS Program for the CDC Growth Charts. 2007; http://www.ced.gov/nccdpdp/dnpa/growthcharts/resources/sas.htm:Accessed 21 August 2008.

37. Jones BL, Nagin DS, Roeder K. A SAS procedure based on mixture models for estimating developmental trajectories. Sociological Methods \& Research. 2001; 29(3):374-93.

38. Nagin DS. Group Based Modeling of Development. Cambridge, MA: Harvard University Press; 2005.

39. Demerath EW, Schubert CM, Maynard LM, et al. Do changes in body mass index percentile reflect changes in body composition in children? Data from the Fels Longitudinal Study. Pediatrics. 2006; 117(3):e487-95. 
40. de Gelder B. Towards the neurobiology of emotional body language. Nat Rev Neurosci. 2006; 7(3):242-9.

41. Niedenthal PM. Embodying emotion. Science. 2007; 316(5827):1002-5.

42. Must A, Strauss RS. Risks and consequences of childhood and adolescent obesity. Int J Obes Relat Metab Disord. 1999; 23(Suppl 2):S2-11.

43. Janicke DM, Harman JS, Kelleher KJ, Zhang J. Psychiatric diagnosis in children and adolescents with obesity-related health conditions. J Dev Behav Pediatr. 2008; 29(4):276-84.

44. Young-Hyman D, Tanofsky-Kraff M, Yanovski SZ, et al. Psychological status and weight-related distress in overweight or at-risk-for-overweight children. Obesity. 2006; 14(12):2249-58.

45. Adams MA, Mannion AF, Dolan P. Personal risk factors for first-time low back pain. Spine. 1999; 24(23):2497-505.

46. Christie HJ, Kumar S, Warren SA. Postural aberrations in low back pain. Arch Phys Med Rehabil. 1995; 76(3):218-24. 
47. Dankaerts W, O'Sullivan P, Burnett A, Straker L. Differences in sitting postures are associated with nonspecific chronic low back pain disorders when patients are subclassified. Spine. 2006; 31(6):698-704.

48. de Looze MP, Kuijt-Evers LF, van Dieen J. Sitting comfort and discomfort and the relationships with objective measures. Ergonomics. 2003; 46(10):985-97.

49. Evcik D, Yucel A. Lumbar lordosis in acute and chronic low back pain patients. Rheumatol Int. 2003; 23(4):163-5.

50. Jackson RP, McManus AC. Radiographic analysis of sagital plane alignment and balance in standing volunteers and patients with low back pain matched for age, sex, and size- a prospective controlled clinical study Spine. 1994; 19(14):1611-8.

51. Korovessis P, Stamatakis M, Baikousis A. Segmental roentgenographic analysis of vertebral inclination on sagittal plane in asymptomatic versus chronic low back pain patients. J Spinal Disord. 1999; 12(2):131-7.

52. Mitchell T, O'Sullivan PB, Burnett AF, Straker L, Smith A. Regional differences in lumbar spinal posture and the influence of low back pain. BMC Musculoskelet Disord. 2008; 9(1):152.

53. Ohlen G, Wredmark T, Spangfort E. Spinal sagittal configuration and mobility related to low-back pain in the female gymnast. Spine. 1989; 14(8):847-50. 
54. Oosterwijk S, Rotteveel M, Fischer AH, Hess U. Embodied emotion concepts: How generating words about pride and disappointment influences posture. European Journal of Social Psychology. 2009; 39(3):457-66.

55. Wilson VE, Peper E. The effects of upright and slumped postures on the recall of positive and negative thoughts. Appl Psychophysiol Biofeedback. 2004; 29(3):189-95.

56. Christensen ST, Hartvigsen J. Spinal curves and health: a systematic critical review of the epidemiological literature dealing with associations between sagittal spinal curves and health. J Manipulative Physiol Ther. 2008; 31(9):690-714. 


\section{Captions to Figures}

Figure 1: Angular measures used to describe sagittal spinal alignment in a usual standing position.

Figure 2: Trajectories of body mass index (BMI) z-scores in a six class model following latent class group analysis. Follow-up points are age in years.

Figure 3: Characteristics of the four sagittal standing posture subgroups. Percentages represent group membership numbers.

Figure 4: Body mass index (BMI) z-score trajectory frequencies within the postural subgroups. 
Figure 1: Angular measures used to describe sagittal spinal alignment in a usual standing position.

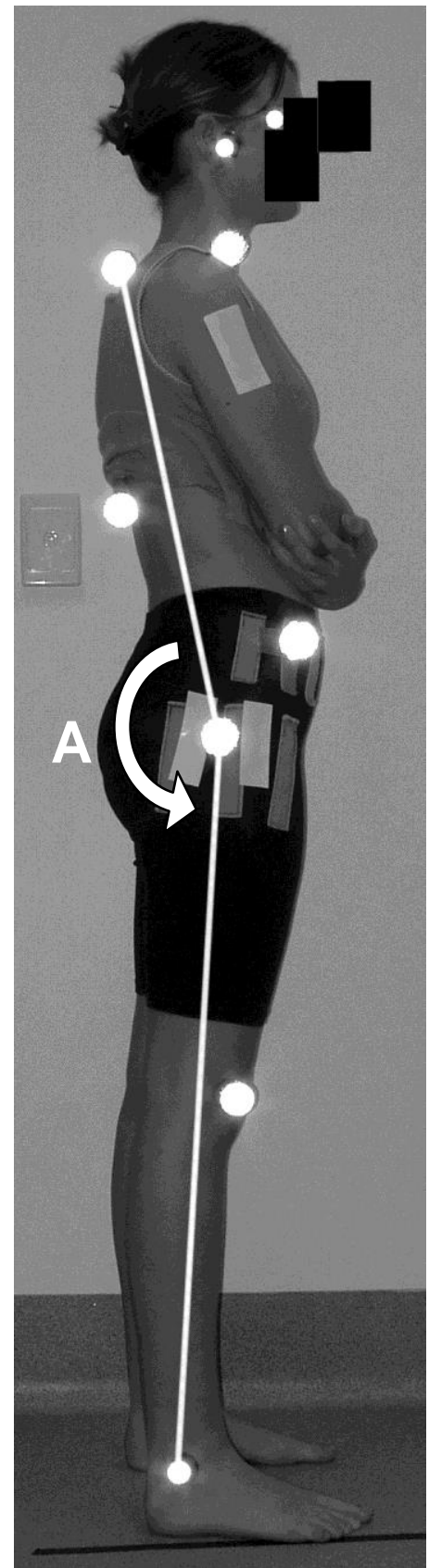

A. Sway Angle

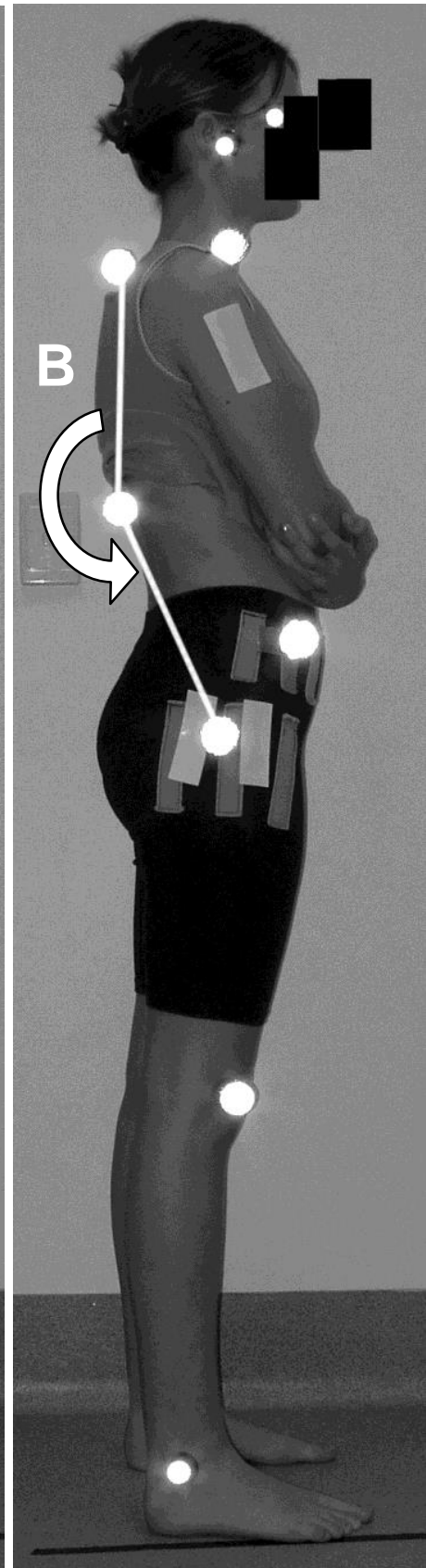

B. Trunk Angle

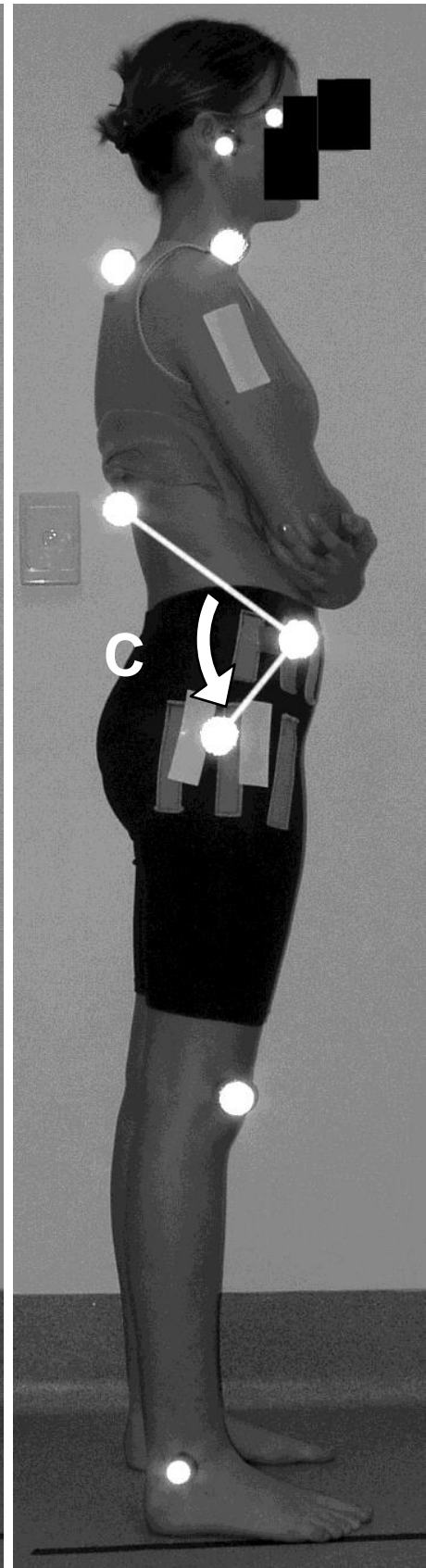

C. Lumbar Angle 
Figure 2: Trajectories of body mass index (BMI) z-scores in a six class model following latent class group analysis. Follow-up points are age in years.

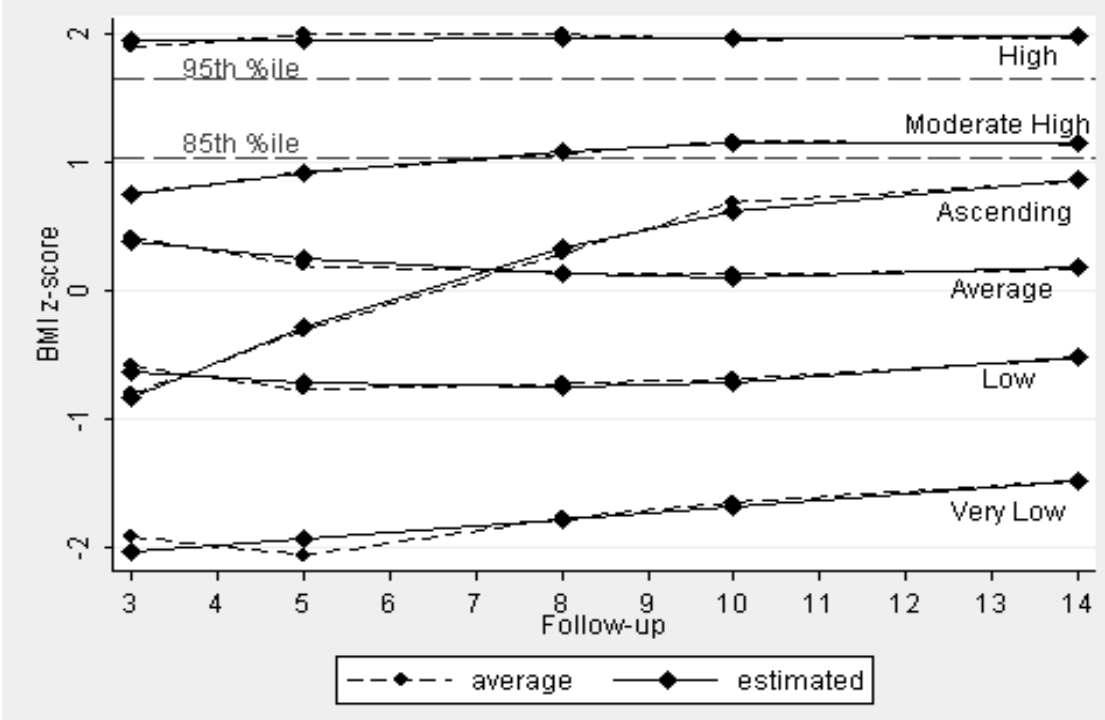


Figure 3: Characteristics of the four sagittal standing posture subgroups. Percentages represent group membership numbers.

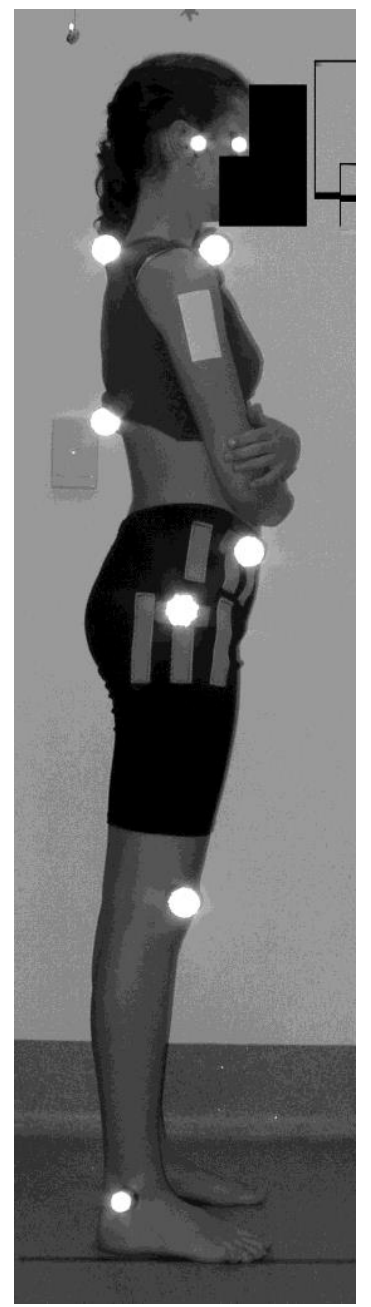

$\underline{\text { Neutral }}$

$(28.6 \%)$

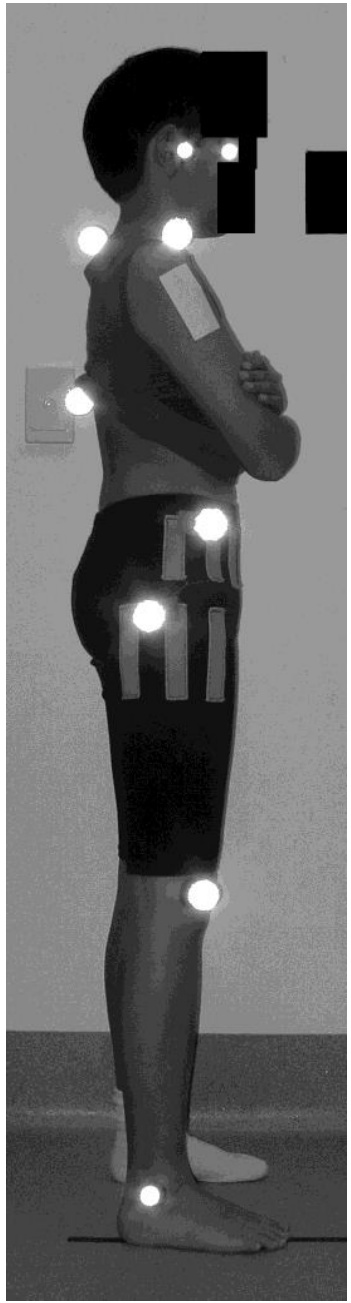

Flat

Forward Trunk Lean -higher sway angle

Less Kyphosis

-lower trunk angle

Flattened Lordosis -greater lumbar angle $(22.4 \%)$

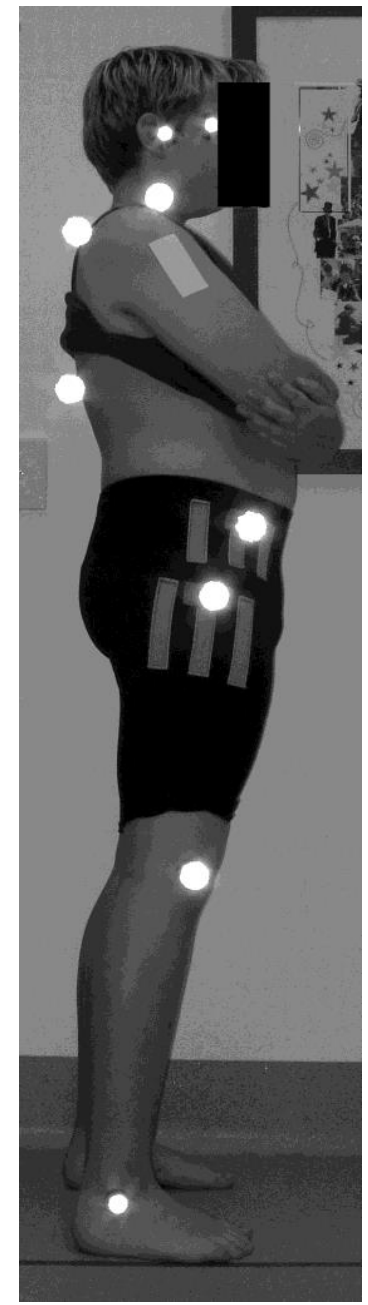

Sway

Backward Trunk Lean -lower sway angle

More Kyphosis -slightly higher trunk angle

Reduction of Lordosis -slightly greater lumbar angle $(26.8 \%)$

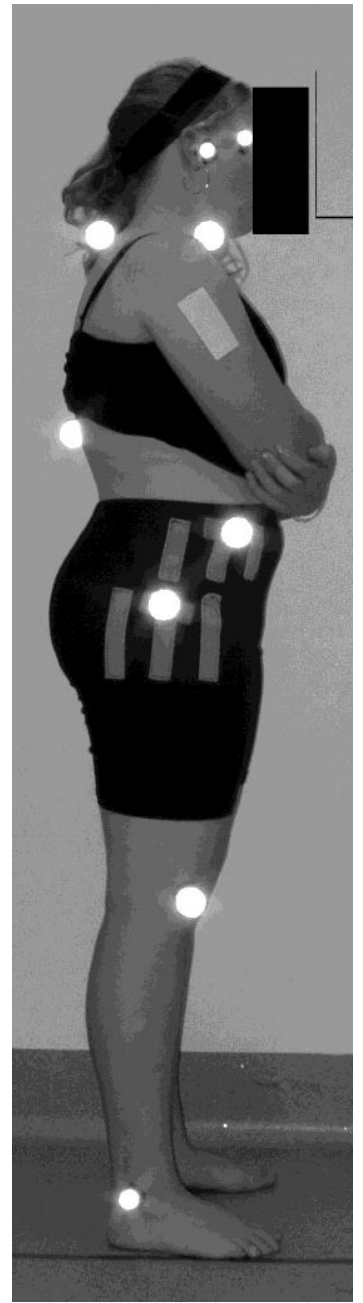

Hyperlordotic Neutral Trunk Lean More Kyphosis - higher trunk angle Increased Lordosis -lower lumbar angle $(22.2 \%)$ 
Figure 4: Body mass index (BMI) z-score trajectory frequencies within the postural subgroups.

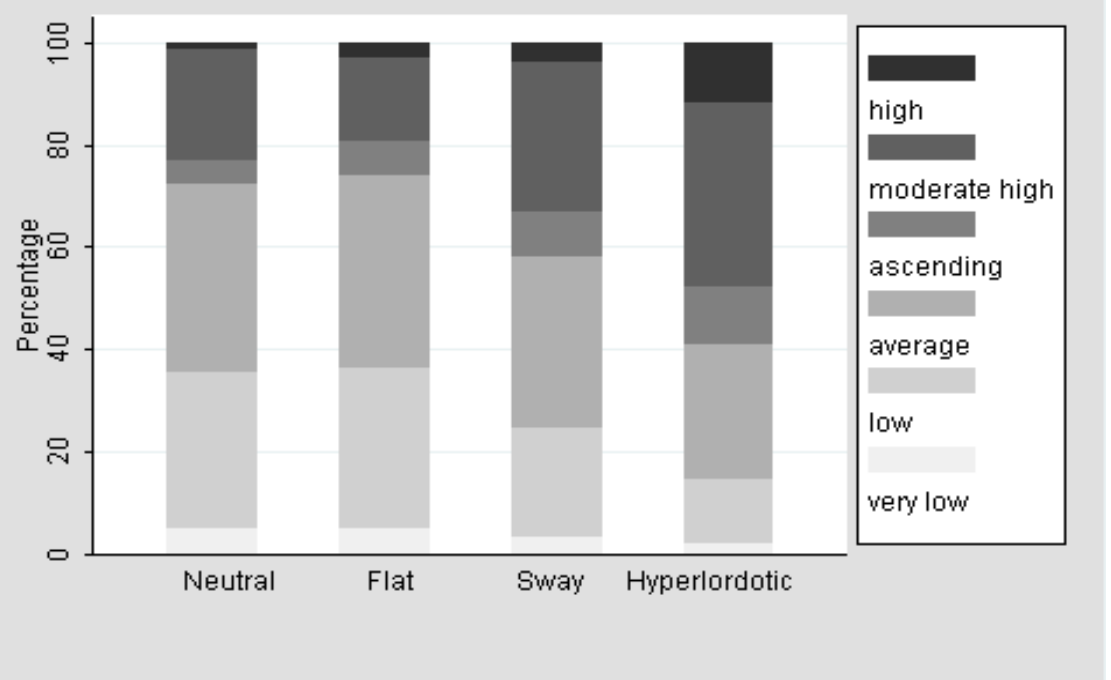


Table 1: Frequencies and profiles of postural subgroups on three postural angles (sd = standard deviation)

\begin{tabular}{|c|c|c|c|c|c|c|c|c|}
\hline \multirow[b]{2}{*}{ Cluster } & \multirow[b]{2}{*}{$\begin{array}{c}\% \\
(\mathrm{~N})\end{array}$} & \multirow[b]{2}{*}{$\begin{array}{c}\% \\
\text { male } \\
(\mathrm{N})\end{array}$} & \multicolumn{2}{|c|}{ Sway Angle } & \multicolumn{2}{|c|}{ Trunk Angle } & \multicolumn{2}{|c|}{ Lumbar Angle } \\
\hline & & & Mean & sd & Mean & sd & Mean & sd \\
\hline Neutral & $\begin{array}{c}28.6 \\
(392)\end{array}$ & $\begin{array}{l}45.9 \\
(180)\end{array}$ & 166.5 & 4.2 & 201.7 & 6.1 & 86.5 & 6.9 \\
\hline Flat & $\begin{array}{c}22.4 \\
(308)\end{array}$ & $\begin{array}{l}63.0 \\
(194)\end{array}$ & 169.4 & 4.2 & 205.9 & 6.8 & 100.5 & 7.5 \\
\hline Sway & $\begin{array}{c}26.8 \\
(368)\end{array}$ & $\begin{array}{l}50.0 \\
(184)\end{array}$ & 160.8 & 4.0 & 211.3 & 7.2 & 98.7 & 8.1 \\
\hline $\begin{array}{l}\text { Hyper- } \\
\text { lordotic }\end{array}$ & $\begin{array}{c}22.2 \\
(305)\end{array}$ & $\begin{array}{l}43.9 \\
(134)\end{array}$ & 164.0 & 4.7 & 215.1 & 6.9 & 82.7 & 8.0 \\
\hline
\end{tabular}


Table 2: Associations between BMI z-score trajectory classes and the sagittal standing postural subgroups, adjusted for gender $(\mathrm{RR}=$ risk ratio, $\mathrm{CI}$ = confidence interval)

\begin{tabular}{|c|c|c|c|c|c|c|}
\hline & \multicolumn{6}{|c|}{ Posture Group } \\
\hline & \multicolumn{2}{|c|}{ Hyperlordotic } & \multicolumn{2}{|c|}{ Sway } & \multicolumn{2}{|l|}{ Flat } \\
\hline & $\begin{array}{c}\text { RR } \\
(95 \% \mathrm{Cl})\end{array}$ & $\bar{p}$ & $\begin{array}{c}\text { RR } \\
(95 \% \mathrm{Cl})\end{array}$ & $\bar{p}$ & $\begin{array}{c}\text { RR } \\
(95 \% \mathrm{Cl})\end{array}$ & $\bar{p}$ \\
\hline Very Low & $\begin{array}{c}0.63 \\
(0.25 \text { to1.55) }\end{array}$ & 0.31 & $\begin{array}{c}0.75 \\
(0.36 \text { to1.58) }\end{array}$ & 0.45 & $\begin{array}{c}0.98 \\
(0.48 \text { to1.98) }\end{array}$ & 0.95 \\
\hline Low & $\begin{array}{c}0.57 \\
(0.36 \text { to } 0.89)\end{array}$ & 0.015 & $\begin{array}{c}0.75 \\
(0.52 \text { to1.10) }\end{array}$ & 0.14 & $\begin{array}{c}0.98 \\
(0.67 \text { to } 1.41)\end{array}$ & 0.90 \\
\hline Moderate & $\begin{array}{l}\text { Reference } \\
\text { Category }\end{array}$ & & $\begin{array}{l}\text { Reference } \\
\text { Category }\end{array}$ & & $\begin{array}{l}\text { Reference } \\
\text { Category }\end{array}$ & \\
\hline Ascending & $\begin{array}{c}3.47 \\
(1.85 \text { to } 6.53)\end{array}$ & $<0.001$ & $\begin{array}{c}2.07 \\
\text { (1.11 to } 3.87)\end{array}$ & 0.023 & $\begin{array}{c}1.44 \\
(0.73 \text { to2.84) }\end{array}$ & 0.29 \\
\hline High & $\begin{array}{c}2.30 \\
(1.55 \text { to } 3.41)\end{array}$ & $<0.001$ & $\begin{array}{c}1.46 \\
(1.01 \text { to } 2.12)\end{array}$ & 0.047 & $\begin{array}{c}0.72 \\
(0.47 \text { to } 1.10)\end{array}$ & 0.13 \\
\hline \multirow[t]{3}{*}{ Very High } & $\begin{array}{c}10.91 \\
(4.40 \text { to } 27.04)\end{array}$ & $<0.001$ & $\begin{array}{c}2.85 \\
\text { (1.07 to } 7.57)\end{array}$ & 0.036 & $\begin{array}{c}1.70 \\
(0.58 \text { to } 4.93)\end{array}$ & 0.58 \\
\hline & \multicolumn{4}{|c|}{$\begin{array}{c}\text { Posture Angle } \\
\text { Trunk }\end{array}$} & Sway & \\
\hline & $\begin{array}{c}\text { Adjusted } \\
\left.\text { difference }{ }^{0}\right) \\
(95 \% \mathrm{Cl})\end{array}$ & $p$ & $\begin{array}{c}\text { Adjusted } \\
\text { difference }\left(^{0}\right) \\
(95 \% \mathrm{Cl})\end{array}$ & $p$ & $\begin{array}{c}\text { Adjusted } \\
\text { difference }\left(^{0}\right) \\
(95 \% \mathrm{Cl})\end{array}$ & $p$ \\
\hline Very Low & $\begin{array}{c}-0.1 \\
(-2.9-2.7)\end{array}$ & 0.94 & $\begin{array}{l}-1.4 \\
(-3.6 \text { to } 0.8)\end{array}$ & 0.21 & $\begin{array}{c}2.3 \\
(0.9 \text { to } 3.8)\end{array}$ & 0.002 \\
\hline Low & $\begin{array}{c}1.0 \\
(-0.4 \text { to } 2.5)\end{array}$ & 0.16 & $\begin{array}{c}-1.7 \\
(-2.8 \text { to }-0.6)\end{array}$ & 0.003 & $\begin{array}{c}-0.0 \\
(-0.8 \text { to } 0.7)\end{array}$ & 0.95 \\
\hline Moderate & $\begin{array}{l}\text { Reference } \\
\text { Category }\end{array}$ & & $\begin{array}{l}\text { Reference } \\
\text { Category }\end{array}$ & & $\begin{array}{l}\text { Reference } \\
\text { Category }\end{array}$ & \\
\hline Ascending & $\begin{array}{c}-1.7 \\
(-3.9-0.4)\end{array}$ & 0.12 & $\begin{array}{c}3.4 \\
(1.7 \text { to } 5.0)\end{array}$ & $<0.001$ & $\begin{array}{c}-0.2 \\
(-1.8 \text { to }-0.4)\end{array}$ & 0.71 \\
\hline High & $\begin{array}{c}-2.8 \\
(-4.3 \text { to }-1.4)\end{array}$ & $<0.001$ & $\begin{array}{c}3.4 \\
(2.3 \text { to } 4.6)\end{array}$ & $<0.001$ & $\begin{array}{c}-1.1 \\
(-1.8 \text { to }-0.4)\end{array}$ & 0.004 \\
\hline Very High & $\begin{array}{c}-3.2 \\
(-5.7 \text { to }-0.7)\end{array}$ & 0.013 & $\begin{array}{c}10.5 \\
(8.6 \text { to } 12.5)\end{array}$ & $<0.001$ & $\begin{array}{c}-0.4 \\
(-1.7 \text { to } 0.9)\end{array}$ & 0.59 \\
\hline
\end{tabular}

